\title{
The effect of Ellagic acid on sleep quality in patients with type 2 diabetes: a randomized double blind clinical trial
}

\author{
Mahnaz Ghadimi ${ }^{1}$ • Sima Hashemipour ${ }^{2,3}$ - Mohamadreza Rashidi Nooshabadi ${ }^{4}$ Maria Kavianpour $^{5}$. \\ Hossein Khadem Haghighian ${ }^{1,3}$ (D)
}

Received: 24 April 2020 /Accepted: 2 July 2020

(C) Research Society for Study of Diabetes in India 2020

\begin{abstract}
Background Oxidative stress can reduce the quality of sleep in patients with type 2 diabetes. Antioxidants such as polyphenols may increase sleep quality by improving oxidative stress conditions.

Objective Considering the antioxidant properties of Ellagic acid (EA), this study was designed to evaluate the effect of EA on sleep quality in diabetic patients.

Methods In this study, 44 diabetic patients were recruited. Patients who met the inclusion criteria that were randomly allocated consumed a capsule containing $180 \mathrm{mg}$ of EA per day $(n=22)$ or placebo $(n=22)$ for 8 weeks. Anthropometric factors, physical activity, food intake, and Petersburg's Sleep Quality (PSQI) questionnaire were assessed at the beginning and end of the study. Kolmogorov-Smirnov test, paired sample $t$ test and independent sample $t$ test were used to analyze the data.

Results At the end of the study, the mean scores of PSQI and sleep subgroups in the intervention group were significantly lower than in the placebo group $(p<0.05)$. According to intragroup comparisons, these changes were significant in the intervention group at the end of the study compared to the beginning of the study $(p<0.05)$ and were not significant in the placebo group $(p>0.05)$.

Conclusion According to these findings, intake of EA may help to improve the sleep quality in patients with type 2 diabetes. These effects may be due to the antioxidant effects of this polyphenol.
\end{abstract}

Keywords Ellagic acid $\cdot$ Sleep quality $\cdot$ Stress oxidative $\cdot$ Type 2 diabetes

IRCT code IRCT20141025019669N13

\author{
Abbreviations \\ AGEs Advanced glycation end products \\ BMI Body mass index \\ DM Diabetes mellitus \\ EA Ellagic acid
}

$\begin{array}{ll}\text { FBS } & \text { Fasting blood sugar } \\ \text { GPx } & \text { Glutathione peroxidase } \\ \text { GSH } & \text { Glutathione } \\ \text { GSSG } & \text { Oxidized glutathione } \\ \mathrm{HbA}_{1} \mathrm{c} & \text { Hemoglobin } \mathrm{A}_{1} \mathrm{c}\end{array}$

Maria Kavianpour and Hossein Khadem Haghighian contributed equally to this work.

Maria Kavianpour

Kavianpour.maria@gmail.com

$\triangle$ Hossein Khadem Haghighian

khademnut@yahoo.com

1 Department of Nutrition, School of Health, Qazvin University of Medical Sciences, Qazvin, Iran

2 Department of Internal Medicine, Velayat Clinical Research Development Unit, Qazvin University of Medical Sciences, Qazvin, Iran
3 Metabolic Diseases Research Center, Research Institute for Prevention of Non-Communicable Diseases, Qazvin University of Medical Sciences, Qazvin, Iran

4 Department of Pharmacology and Toxicology, School of Pharmacy, Ahvaz Jundishapur University of Medical Sciences, Ahvaz, Iran

5 Department of Tissue Engineering and Applied Cell Sciences, Faculty of Advanced Technologies in Medicine, Tehran University of Medical Sciences, Tehran, Iran 